\title{
MIDLINE NASAL DERMOIDS PRESENTING LIKE DISCHARGING LACRIMAL SAC MUCOCOELES
}

\author{
IRENE WHELEHAN AND GEOFFREY E. ROSE \\ London
}

\begin{abstract}
SUMMARY
Two cases of midline intranasal dermoid cysts presenting like discharging lacrimal sac mucocoeles in children are described. The diagnosis of this rare condition is suggested by the presence of midline nasal cutaneous dimples, although these may be associated with isolated anomalies such as nasal dermoid cyst, encephalocoele or glioma.
\end{abstract}

Congenital obstruction of the lacrimal drainage system, with symptomatic epiphora, is present in up to $20 \%$ of the newborn ${ }^{1}$ and is thought to be due to non-perforation of a membrane at the lower end of the nasolacrimal duct. Ninety-five per cent of affected babies will improve spontaneously by 12 months. ${ }^{1}$ Where patency does not occur the child may develop a mucocoele or chronic dacryocystitis with persistent watering, mucopurulent discharge, and occasionally fistula formation; dacryocystorhinostomy (DCR) will be necessary for resolution of the fistula. Less commonly, the obstructed system is invaded with pyogenic organisms and the child develops acute dacryocystitis, which may be complicated by spontaneous discharge to the skin and chronic fistula formation (Fig. 1).

We describe two cases, referred as lacrimal fistula that developed after apparent acute dacryocystitis, in which the underlying lesion was a midline intranasal dermoid cyst.

\section{Case 1}

\section{CASE REPORTS}

A 3-year-old boy presented with a 6-month history of discharge from the left lacrimal sac area following incision and drainage of an acute abscess at the referring hospital. He had a history of intermittent watering, but no previous injury. On examination there was florid granulomatous reaction below the left medial canthal tendon and normal lacrimal puncta (Fig. 2); the appearance was similar to that

Correspondence to: Mr G. E. Rose, MS, MRCP, FRCS, Adnexal Service, Moorfields Eye Hospital, City Road, London EC1V 2PD, UK. of chronic dacryocystitis with fistula formation as illustrated in Fig. 1.

Under anaesthesia, syringing was patent to the nose, dacryocystography was not performed, and instead exploration was undertaken for a lacrimal sac diverticulum. A mass straddling the midline in the superior half of the nasal space (Fig. 3) was isolated and excised and subsequent histology confirmed a dermoid cyst. Later systemic examination of the child revealed a small midline dimple at the tip of the nose (Fig. 4). A remaining cord of cells along the nasal septum was subsequently resected through a transoral approach.

\section{Case' 2}

A 4-year-old girl was referred with chronically discharging fistula at the left medial canthus which had recurred 2 months after attempted DCR prior to referral. The child had a constantly watery left eye since a few weeks old, and she also had spina bifida occulta.

The skin around the left scar was inflamed, purulent material was discharging from a chronic fistula at the surgical scar (Fig. 5) and a midline nasal dimple was noted half way between the glabella and the tip of the nose.

Dacryocystography under anaesthetic revealed a patent nasolacrimal duct to the inferior meatus of the nose, with no evidence of previous lacrimal surgery (Fig. 6), and sinography showed a fistulous tract leading from the surgical scar to the nasal dimple (Fig. 7); oily contrast was shown to exit from the nasal dimple (Fig. 8).

The patient subsequently underwent midfacial degloving for total excision of her dermoid, which proved to be an extensive lesion running from the punctum on the tip of the nose, through the nasal septum, dividing the nasal bones, extending into the crista galli and into the anterior cranial fossa, where it was attached to the dura. There was also a separate tract running from the nasal bones to the left medial canthal area. 


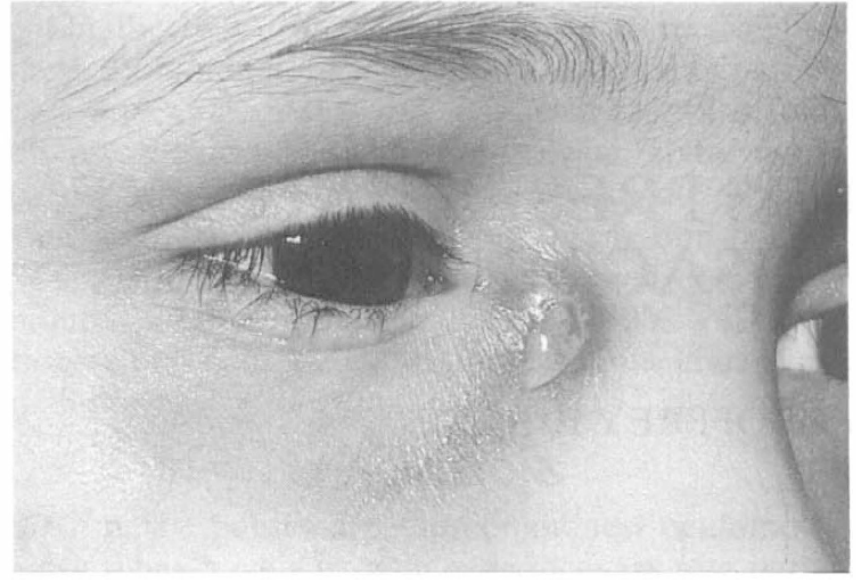

(a)

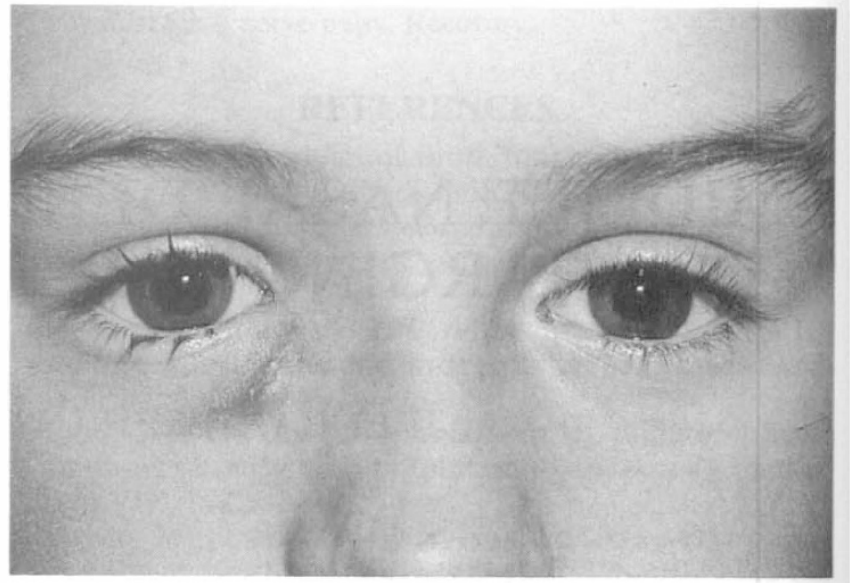

(b)

Fig. 1. (a) and (b) Children with lacrimal sac mucocoeles, discharging onto the skin near the medial canthus.

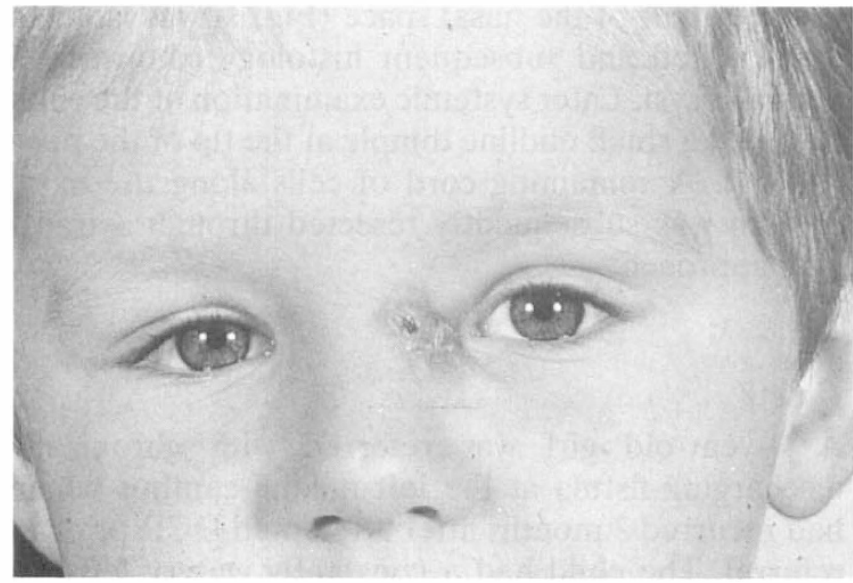

Fig. 2. Case 1. A 3-year-old with a 6-month history of intermittent epiphora and a discharging mass below the medial canthal tendon.

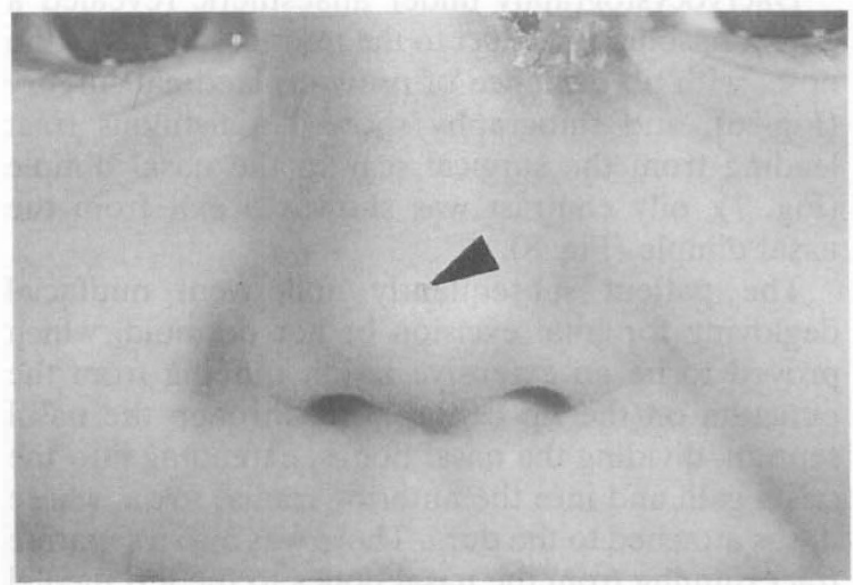

Fig. 4. Case 1. Midline cutaneous dimple (arrow) on the tip of the nose.

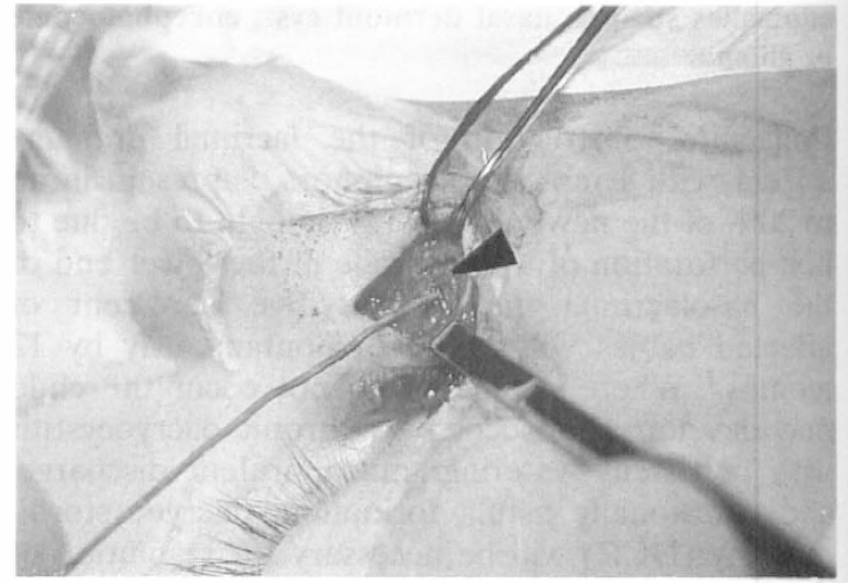

Fig. 3. Case 1. Probe inserted into the dermoid cyst, this occupying the superior half of the anterior nasal space with partial agenesis of the septum and nasal bone. The majority of the dermoid cyst lay within a cavity (arrow) straddling the nasal septum, but a further cord of tissue passed to the nasal tip.

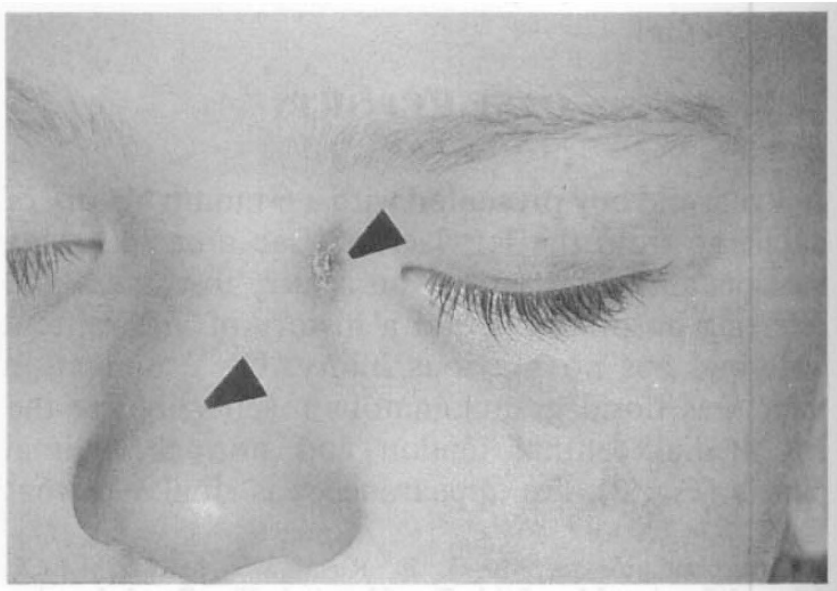

Fig. 5. Case 2. A 4-year-old with chronic discharging fistula (arrow) at the medial canthus and midline cutaneous dimple (arrow). 


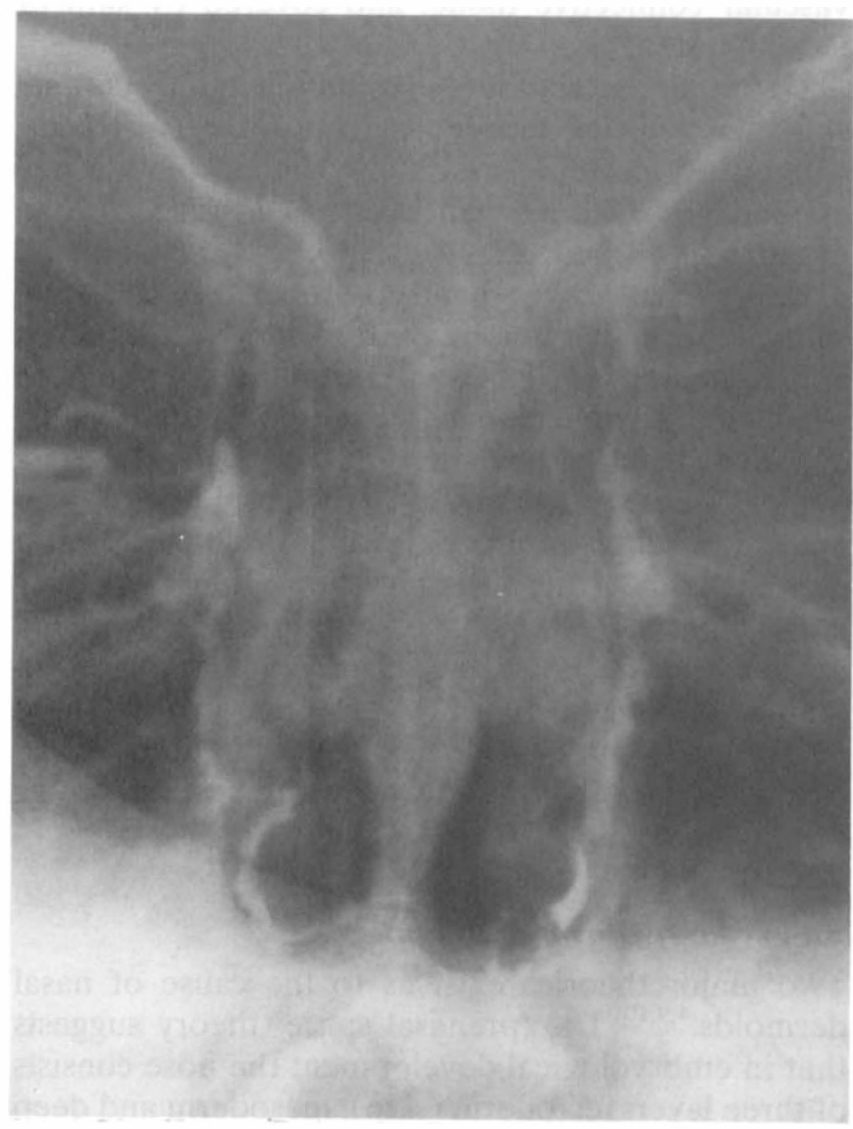

Fig. 6. Case 2. Dacryocystogram showing patent nasolacrimal ducts.

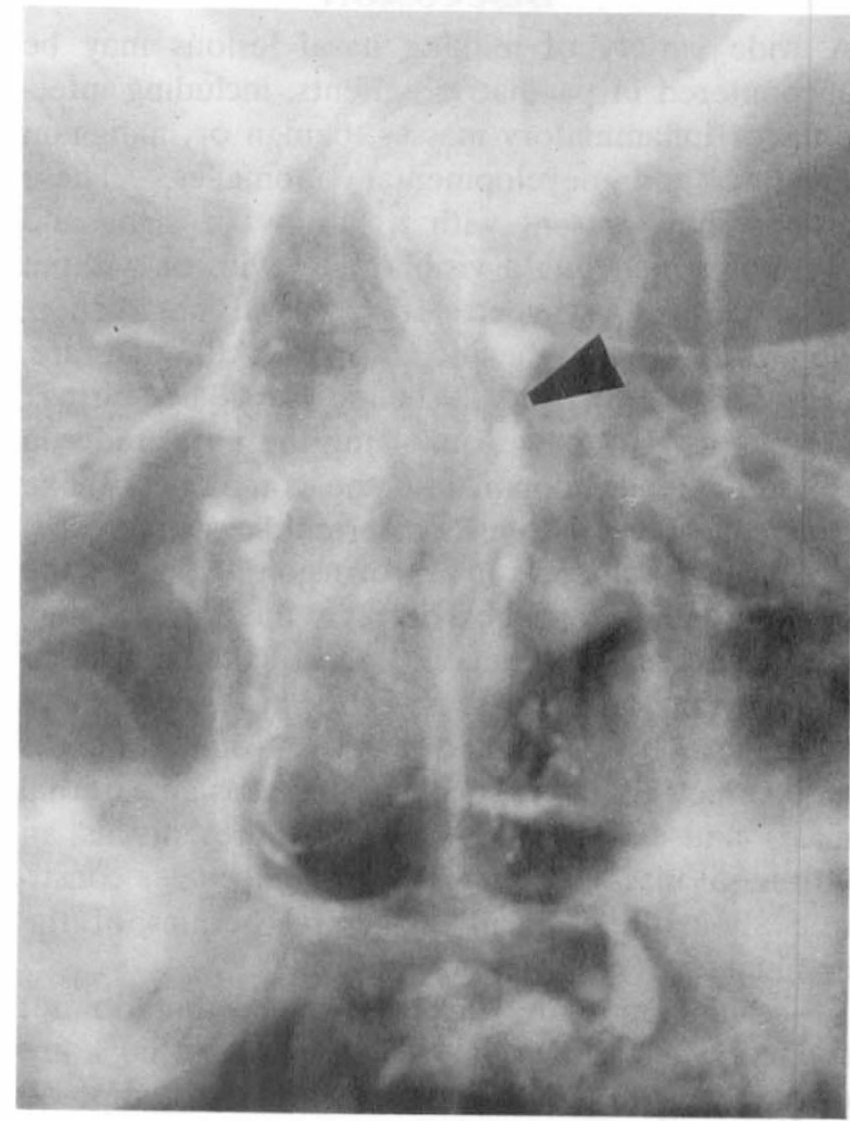

Fig. 7. Case 2. Contrast in the fistulous tract from the surgical scar to the nasal dimple (arrow).

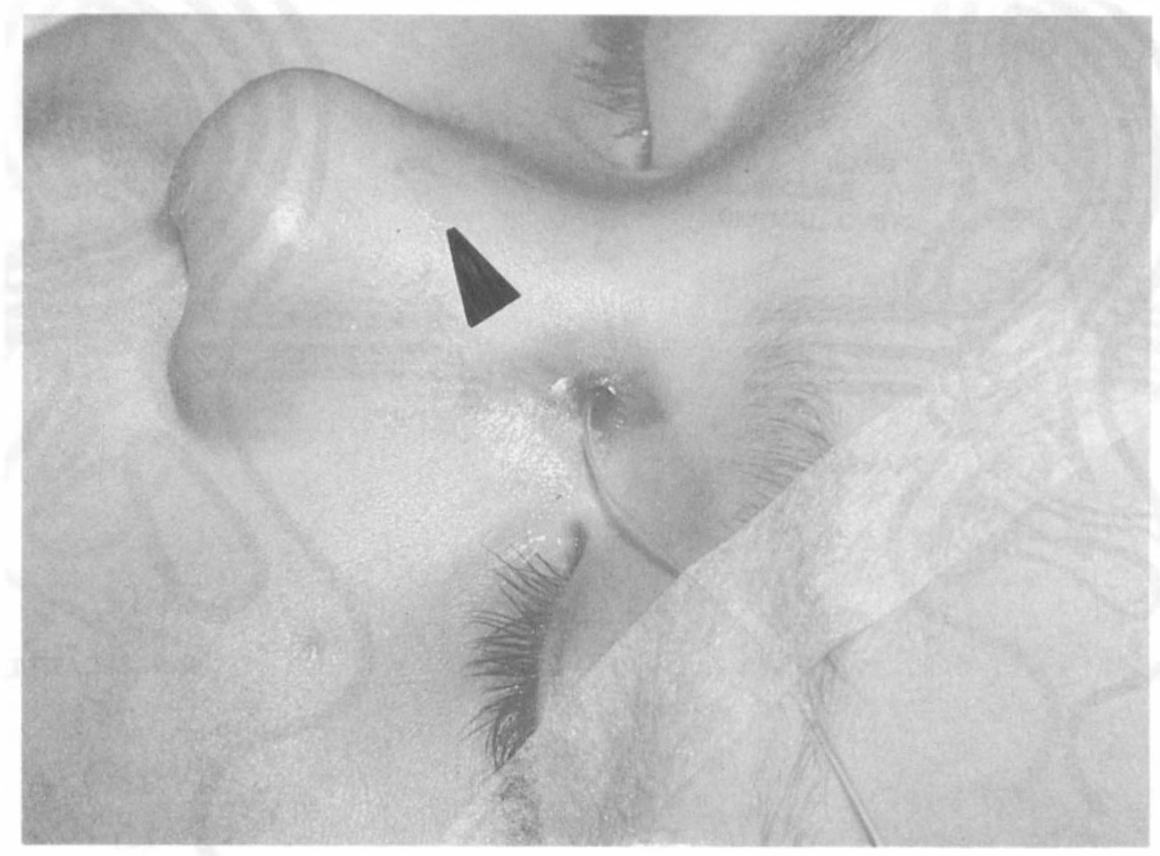

Fig. 8. Case 2. Oily contrast exiting from the nasal dimple (arrow). 


\section{DISCUSSION}

A wide variety of midline nasal lesions may be encountered in paediatric patients, including infectious or inflammatory masses, benign or malignant tumours and developmental anomalies. ${ }^{2}$ These lesions may present with a variety of signs and symptoms including a visible mass with or without nasal deformity, hypertelorism, nasal obstruction, rhinorrhoea, headache and epiphora. Although rare, occurring once in every 20000 to 40000 live births, ${ }^{3}$ the majority of masses involving the nasal radix in children are developmental, the commonest being encephalocoeles, gliomas or dermoid cysts. ${ }^{4}$

An encephalocoele is a protrusion of part of the cranial contents through a defect in the skull and may contain meninges, brain, and part of the ventricular system. On the basis of their location, encephalocoeles may be subdivided into the frontoethmoidal type (which characteristically presents as an external mass) and the basal type (which presents as an intranasal mass). Intranasal encephalocoeles constitute about $10 \%$ of all congenital hernias of the cranium. ${ }^{5}$

Nasal gliomas are encephalocoeles that do not connect with intracranial structures; about $60 \%$ are external and $30 \%$ intranasal. ${ }^{4}$ Gliomas are composed of astrocytic neuroglial cells, mixed with fibrous and

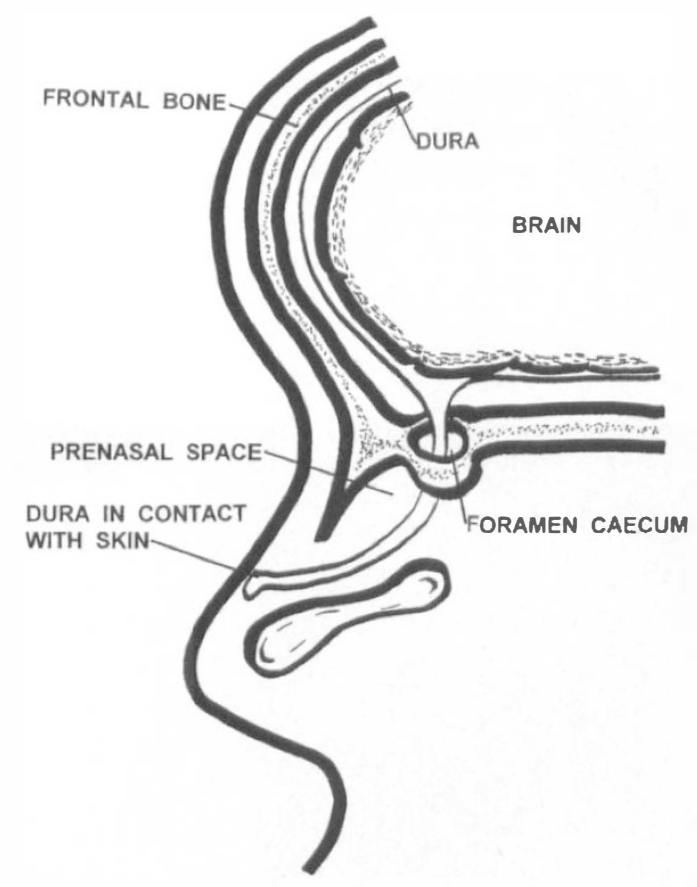

(a) vascular connective tissue, and covered by skin or nasal mucosa.

Dermoids are ectodermal cysts which may contain skin, hair follicles, sebaceous glands or sweat glands, whereas epidermoid cysts lack the deeper dermal appendages. One per cent of dermoids occur in the nasal region and they constitute $4-12 \%$ of all dermoid cysts of the head and neck. ${ }^{6}$ If a dermal sinus is present it may be identified as a cutaneous defect leading inward from the midline of the nose which, if it is connected with a dermoid cyst, is called a dermal fistula. Nasal dermoids may present as a mass at - or a broadening of - the nasal bridge, with intermittent inflammation, or as a discharge from a dermal fistula (this fistula may contain projecting hairs). Dermal fistulae may be superficial, with no deep extension, may end blindly within the deep midline structures of the nose, or may extend intracranially in $4-10 \%$ of cases; ${ }^{7,8}$ intracranial extension may be associated with life-threatening complications, such as meningitis.

\section{Embryology of Nasal Dermoids}

Two major theories exist as to the cause of nasal dermoids. ${ }^{4,9,10}$ The 'prenasal space' theory suggests that in embryological development the nose consists of three layers: ectoderm (skin), mesoderm and deep layer of cartilage. The frontal and nasal bones form

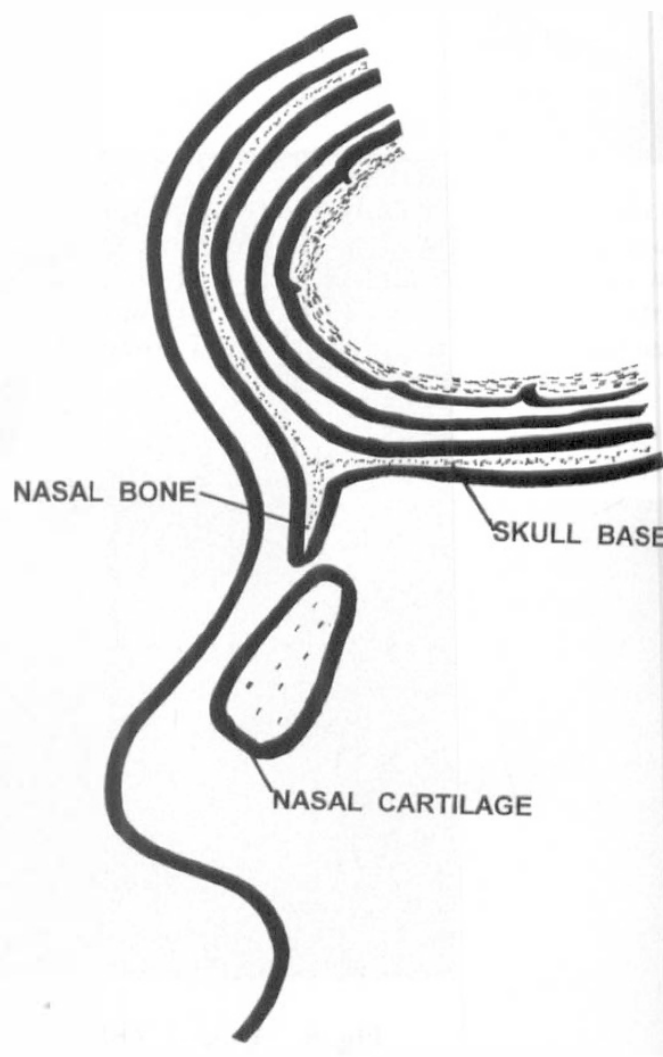

(b)

Fig. 9. (a) and (b) Normal embryology of the anterior skull base and nose. (Redrawn after Hughes et al. ${ }^{4}$ ) 


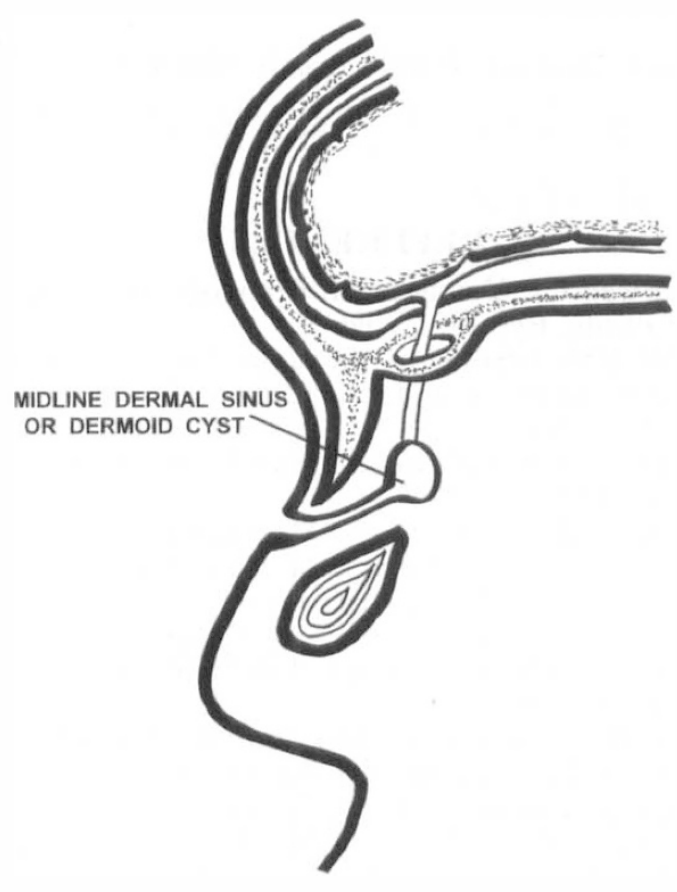

(a)

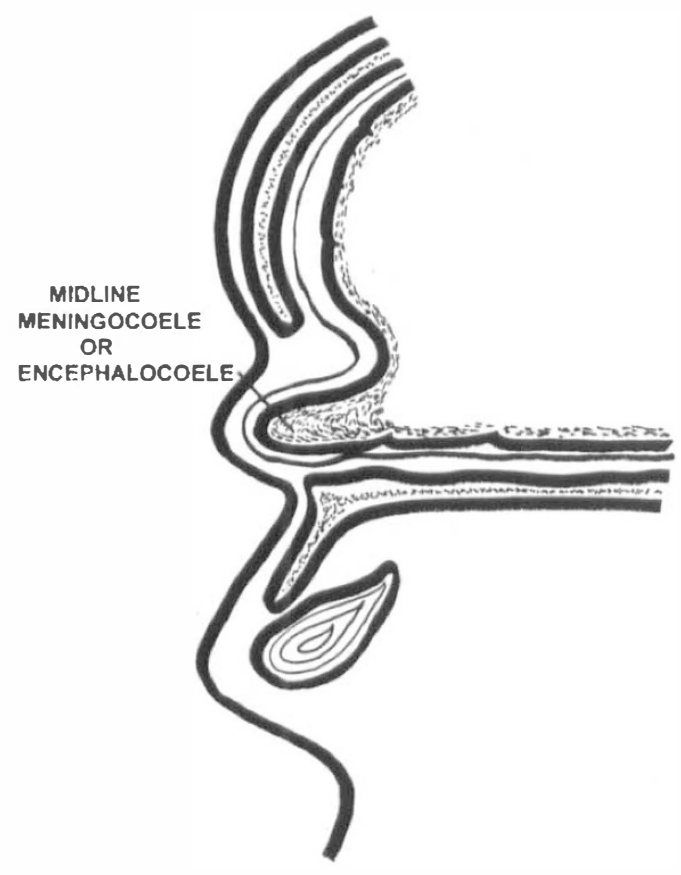

(c)

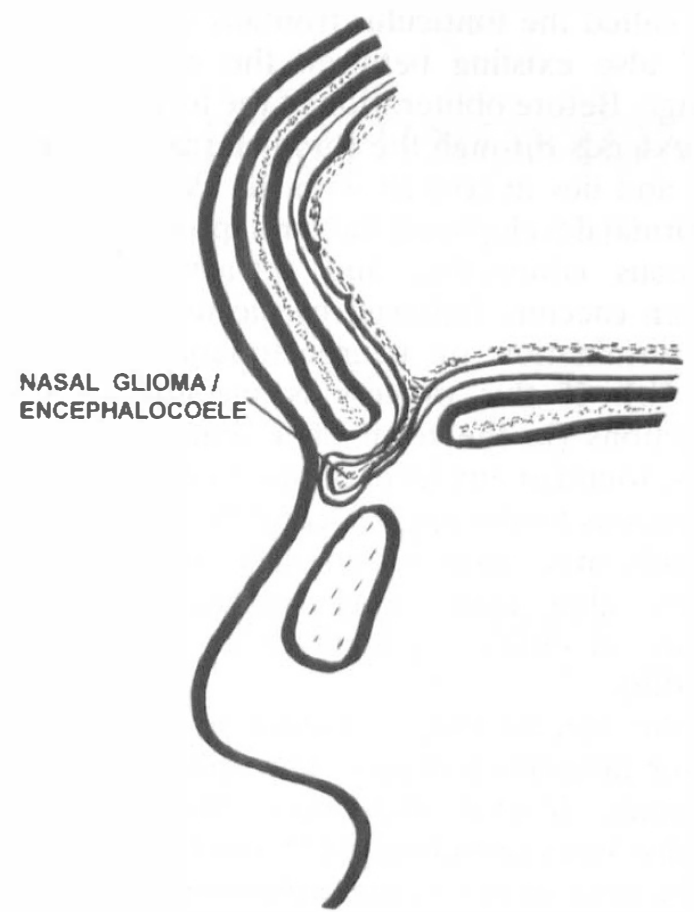

(b)

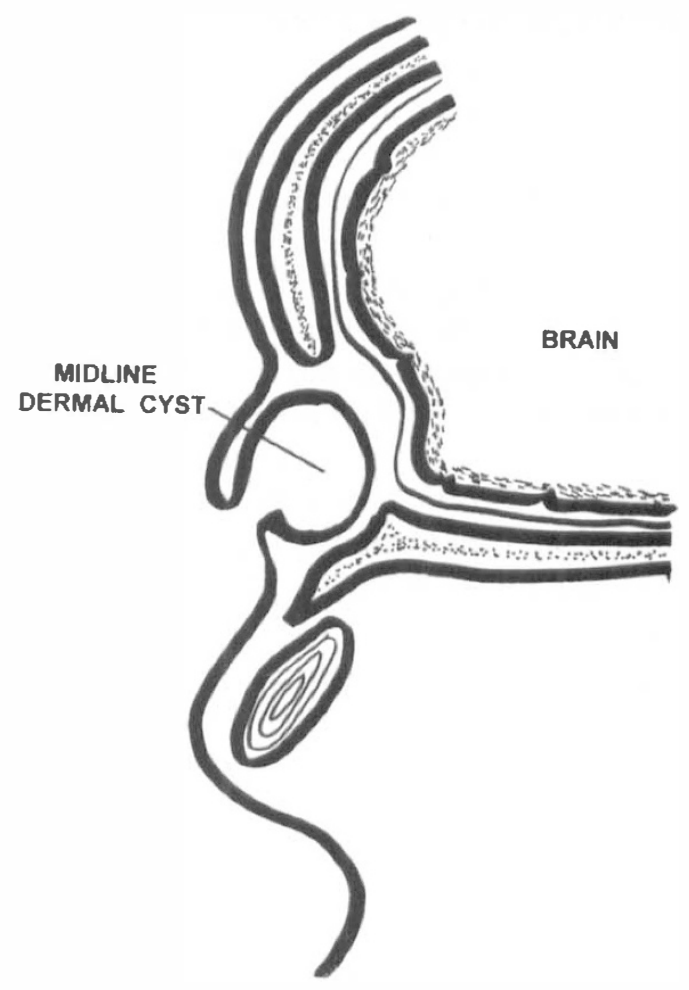

(d)

Fig. 10. (a)-(d) Anomalies of anterior cranial and nasal development. (Redrawn after Hughes et al. ${ }^{4}$ ) 
in the mesodermal layer, but are separated by a space called the fonticulus frontalis with a 'prenasal space' also existing between the nasal bone and cartilage. Before obliteration of the foramen caecum, dura extends through the foramen into the prenasal space and lies in contact with the skin (Fig. 9a). In the normal development the dural projection loses its cutaneous connection and retracts through the foramen caecum, followed by closure of the latter, with termination of neuroectodermal connection (Fig. 9b). If this process is incomplete, dermal connections (in the form of a sinus tract or cyst) may be found at any level of this pathway (Fig. 10a). If cutaneous tissues migrate centrally along this path, dermoids may form intranasally or intracranially; likewise glial tissue may extend extracranially, resulting in either a glioma or an encephalocoele (Fig. 10b).

In the second theory, failure of closure of the anterior neuropore occurs. The space between the developing frontal and nasal bones (fonticulus frontalis) fuses completely with the foramen caecum and the area of the future cribriform plate, thereby separating the intracranial contents from the extracranial structures and the nose. A failure of closure of the anterior neuropore or of bony fusion may result in herniation of intracranial contents and the formation of an encephalocoele (Fig. 10c). If invagination of dermal elements occurs along this midline of fusion, dermoid cysts and sinuses may develop (Fig. 10d).

Key words: Dermoid, Dimple (nasal), Mucocoele (lacrimal), Nasal.

\section{REFERENCES}

1. MacEwen CJ, Young JDH. Epiphora during the first year of life. Eye 1991;5:596-9.

2. Sweet RM. Lesions of the nasal radix in paediatric patients: diagnosis and management. Southern Med J 1992;85:164-9.

3. Harley EH. Paediatric congenital masses. Ear Nose Throat J 1991;70:28-37.

4. Hughes GB, Sharpino G. Management of the congenital midline nasal mass: a review. Head Neck Surg 1980;2:222-33.

5. Suwanwela C, Suwanwela N. A morphological classification of sincipital encephalomeningocoeles. J Neurosurg 1972;36:201-11.

6. Naidich TP, Bauer BS, McLone DG, Kernahan DA, Tonita T. Nasal dermal sinuses and cysts. Acta Radiol Suppl (Stockholm) 1986;369:322-4.

7. Morrisey MSC, Bailey CM. External rhinoplasty approach for nasal dermoids in children. Ear Nose Throat J 1991;70:445-9.

8. Bradley PJ. Nasal dermoids in children. Int $\mathbf{J}$ Paediatr Otorhinolaryngol 1983;3:63-72.

9. Sessions RB. Nasal dermal sinuses: new concepts and explanations. Laryngoscope 1982;92(Suppl 29):1-28.

10. Frodel JL, Wayne F, Raisis J. The nasal dermoid. Otolaryngol Head Neck Surg 1989;101:392-6. 